\title{
Epidemiology and treatment of 23 musicians with task specific tremor
}

\author{
André Lee*, Shinichi Furuya and Eckart Altenmüller
}

\begin{abstract}
Background: Task specific tremors in musicians have been mainly described as primary bowing tremor in string instrumentalists in relatively small sample sizes. Our aim was to describe epidemiology, risk factors, phenomenology and treatment options of this disorder in 23 musicians of different instruments.

Methods: We included 23 professional musicians (4 female, 19 male; mean age $51.5 \pm 11.4$ years) with a TSTM. During anamnesis, clinical examination, by mail or via telephone patients were asked for epidemiological, phenomenological information, risk factors and treatments. We then compared our findings to primary writing tremor, the most common task specific tremor.
\end{abstract}

Results: Age at onset of the TST was $44.6 \pm 13.6$ years and tremor appeared $35.1 \pm 13.5$ years after beginning to play the instrument. The majority of patients were string instrumentalists, followed by woodwind instrumentalists. Other instrumentalists were a guitarist, pianist and percussionist respectively. In contrast to primary writing tremor, we also found proximal muscles of the upper extremity involved in tremor. A positive family history was found in Prior trauma was more common than in primary writing tremor. Treatment with a positive effect on tremor were in order of efficacy: Botulinumtoxin, Primidone, Propranolol, Trihexyphenidyl. No patient had undergone deep brain stimulation.

Conclusion: Task specific tremor in musicians is a heterogeneous disorder with a male gender predominance that shares many commonalities with PWT. The onset age as well as the time between starting to play the instrument and tremor onset has a wide range. Because previous trauma and overuse appear to be risk factors, preventive measures against playing related injuries are necessary. There appears to be a genetic predisposition for TST. No single beneficial medication exists and treatment of patients remains highly individual. It should be discussed, whether deep brain stimulation should be offered not only to patients that do not respond to any other medication but early in the course of the disease.

Keywords: Dystonia, Essential tremor, Movement disorders, Botulinum toxin, Deep brain stimulation

\section{Background}

Task specific tremor in musicians (TSTM) is a highly disabling disorder that occurs only or mainly while playing the instrument and has primarily been described in string instrumentalists as primary bowing tremor (PBT) [1-3]. The most common form of a task specific tremor is primary writing tremor (PWT), first described by Rothwell in 1979 [4]. Two forms can be distinguished: type A tremor (task specific) and type B (position specific) [5]. While there are many studies on epidemiology,

\footnotetext{
* Correspondence: andre.lee@hmtm-hannover.de

Inistitute of Music Physiology and Musicians' Medicine, Hannover University of Music, Drama and Media, Hannover, Germany
}

pathophysiology and treatment of PWT [5-20] only a few studies are available for TSTM [1-3,21]. Thus the sample sizes described so far are small, allowing only for limited conclusions e.g. with regard to risk factors or treatment. The aim of this paper therefore was to describe epidemiological data and treatment in 23 musicians with TSTM at a variety of instruments and compare the findings to PBT and PWT.

\section{Methods}

The study was approved by the local ethics committee and written informed consent was obtained from all participants.

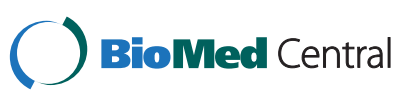

(C) 2014 Lee et al.; licensee BioMed Central Ltd. This is an Open Access article distributed under the terms of the Creative Commons Attribution License (http://creativecommons.org/licenses/by/4.0), which permits unrestricted use, distribution, and reproduction in any medium, provided the original work is properly credited. The Creative Commons Public Domain Dedication waiver (http://creativecommons.org/publicdomain/zero/1.0/) applies to the data made available in this article, unless otherwise stated. 
We included 23 professional musicians (4 female, 19 male; mean age $51.5 \pm 11.4$ years) with a TSTM who were seen at our outpatient clinic. Four violinists with PBT described previously were included. During anamnesis, by mail or via telephone the following information were asked for: Age, age when starting to play the instrument and age at onset of tremor; time between starting to play the instrument and tremor onset; previous trauma; whether the professional position as before tremor was still upheld (e.g. an orchestra musician was still playing in an orchestra); responsiveness to alcohol; family history for movement disorders. Tremor frequency; side of tremor; spreading of tremor to other tasks; treatments and their efficacy. In order to distinguish between kinetic tremor and postural tremor at the instrument, the former and latter was considered type A and B tremor, respectively. However we are aware that this distinction may be debatable (Table 1). Tremor was quantified with electromyogram and accelerometer in 22 patients and the mean frequency is given for those participants. Details will be reported elsewhere.

To assess the gender distribution we applied two $X^{2}$ tests: The first assuming no gender predominance and a second one assuming a gender predominance as in musician's dystonia [22] (f:m =1:4), if the first should reveal a significant difference.

\section{Results}

\section{Epidemiology}

Mean \pm standard deviation (SD) of age of our patients was $51.5 \pm 11.4$ years. Tremor duration was $7.0 \pm 5.1$ years. Patients started their instrument at an age of $9.4 \pm 3.2$ years. Age at onset of the TST was $44.6 \pm 13.6$ years and duration between starting to play the instrument and tremor onset was $35.1 \pm 13.5$ years (Figure 1 ). Of our patients, sixteen were string instrumentalists (69.6\%), four were woodwind instrumentalists (17.4\%) one was a guitarist, pianist and percussionist respectively (each $4.3 \%$ ). Nine patients (39\%) reported a trauma or injury prior to onset of tremor: three had an overuse injury of the respective arm after intensively practicing and playing the instrument, one had an injury of the middle and ring finger and one had a fracture of the radius and ulna. Three patients had shoulder related problems: One had surgery of the shoulder, one surgery of the rotator cuff and one a pain syndrome. Nine patients (39\%) had a positive family history for tremor: Two (9\%) had relatives with Parkinson's disease, of which one had another relative with a tremor disorder. One patient (4\%) had a relative with writer's cramp, four $(17 \%)$ had a relative with essential tremor and one (4\%) had a relative with an unknown tremor disorder. In eight of the patients (35\%) a first-degree relative and in four $(17 \%)$ a second-degree relative was affected. Three patients (13\%) had two affected relatives. Three of the four relatives with essential tremor were first-degree relatives (parents) and one was a second degree relative (grandparents). Two patients did not recall which kind of tremor disorder their relatives were suffering from. In one patient, a first degree relative (father) was suffering from writer's cramp. One patient had a dystonia before onset of TSTM, however at clinical examination no dystonic posturing was visible, and only tremor was discernible.

\section{Phenomenology}

Tremor frequency was $6.5 \pm 0.9 \mathrm{~Hz}$. Ten patients $(43 \%)$ were diagnosed as type B tremor. Fifteen patients (65.2\%) had a wrist tremor, three $(13.0 \%)$ had a forearm pronation supination tremor, four (17.4\%) had an elbow tremor and one $(4.3 \%)$ had a shoulder tremor. In eight patients $(35 \%)$ tremor was at the left upper extremity. Seventeen patients (74\%) were orchestra musicians (including big band), two (9\%) were students, two (9\%) were teachers, one (4\%) was self-employed and one (4\%) was retired. In all patients, tremor started while playing the instrument and remained unilateral. None of the patients developed rest tremor and no other posture than for playing the instrument was affected. In eleven patients (48\%) tremor has spread to other activities. In one patient tremor spread first to shaving, in another to an instrument that was not affected at first, in two tremor appeared when holding a pen, in five when filling a glass with water, one patient had difficulties holding the telephone or typing on a computer keyboard, one had tremor when playing table-tennis. Spreading of tremor occurred between 1 and 6 years after tremor during playing the instrument. Tremor was alcohol responsive in six patients (33\% of 18 patients, five patients did not drink any alcohol). In none of those patients did alcohol lead to a complete remission of tremor, therefore its effect was not rated as sufficient by any of the patients. All opposed taking alcohol before concerts. None of those patients reported a dose response curve to alcohol; however, none had consciously assessed a possible dose-response. Likewise none of those patients reported a rebound effect.

\section{Treatment}

Propranolol was taken in dosages between 5-80 mg/day by 15 patients, of whom 9 had an improvement of tremor (60\%); Trihexyphenidyl was taken by 10 patients at a dosage of $6 \mathrm{mg} /$ day of whom 2 reported an improvement (20\%); four patients took Primidone at $60 \mathrm{mg} /$ day, of whom 3 had an improvement of tremor (75\%); Madopar ${ }^{\circ}$ at a dosage of $62,5 \mathrm{mg} /$ day and Escitalopram at a dosage of $10 \mathrm{mg} /$ day were taken by three patients respectively without effect; Gabapentin at a dosage of $2.4 \mathrm{~g} /$ day, Venlafaxin at a dosage of $150 \mathrm{mg} /$ day, Topiramat at a dosage of $200 \mathrm{mg} /$ day and Lorazepam at a dosage of $1 \mathrm{mg} /$ day was each taken by one patient without effect. Five patients were treated with injections of Botulinumtoxin 
Table 1 Patients' characteristics of all 23 patients with a task specific tremor at the instrument

\begin{tabular}{|c|c|c|c|c|c|c|c|c|c|}
\hline & Gender & Age (yrs) & Instrument & $\begin{array}{l}\text { Age when starting } \\
\text { to play the } \\
\text { instrument (yrs) }\end{array}$ & $\begin{array}{l}\text { Age at onset } \\
\text { of TST (yrs) }\end{array}$ & $\begin{array}{c}\text { Time until TST } \\
\text { onset since beginning } \\
\text { to play (yrs) }\end{array}$ & $\begin{array}{c}\text { TST } \\
\text { duration (yrs) }\end{array}$ & $\begin{array}{l}\text { Tremor } \\
\text { location }\end{array}$ & $\begin{array}{l}\text { Type A } \\
\text { tremor }\end{array}$ \\
\hline Pat. 1 & Male & 40 & Sax & 12 & 27 & 15 & 13 & Wrist & I \\
\hline Pat. 2 & Male & 62 & Violin & 8 & 46 & 38 & 16 & Wrist & r \\
\hline Pat. 3 & Male & 54 & Violin & 12 & 43 & 31 & 11 & Wrist & $r$ \\
\hline Pat. 4 & Male & 48 & Violin & 4 & 40 & 36 & 8 & Wrist & $r$ \\
\hline Pat. 5 & Female & 50 & Violin & 13 & 43 & 30 & 7 & Wrist & $r$ \\
\hline Pat. 6 & Female & 24 & Violin & 5 & 10 & 5 & 14 & Wrist & $r$ \\
\hline Pat. 7 & Male & 59 & Violin & 7 & 58 & 51 & 1 & Wrist & $r$ \\
\hline Pat. 8 & Male & 62 & Violin & 7 & 59 & 52 & 3 & Wrist & $r$ \\
\hline Pat. 9 & Male & 54 & Violin & 10 & 44 & 34 & 10 & Wrist & $r$ \\
\hline Pat. 10 & Male & 54 & Guitar & 11 & 45 & 34 & 9 & Pron/Sup & $r$ \\
\hline Pat. 11 & Female & 58 & Cello & 7 & 56 & 49 & 2 & Pron/Sup & I \\
\hline Pat. 12 & Male & 63 & Cello & 9 & 61 & 52 & 2 & Pron/Sup & 1 \\
\hline Pat. 13 & Male & 56 & Sax & 10 & 47 & 37 & 9 & Wrist & I \\
\hline Pat. 14 & Female & 55 & Oboe & 15 & 50 & 35 & 5 & Elbow & $r$ \\
\hline Pat. 15 & Male & 57 & Violin & 10 & 40 & 30 & 17 & Shoulder & r \\
\hline Pat. 16 & Male & 63 & Viola & 6 & 62 & 56 & 1 & Elbow & 1 \\
\hline Pat. 17 & Male & 23 & Piano & 6 & 19 & 13 & 4 & Wrist & 1 \\
\hline Pat. 18 & Male & 38 & Cello & 5 & 28 & 23 & 10 & Wrist & $r$ \\
\hline Pat. 19 & Male & 58 & Violin & 9 & 57 & 48 & 1 & Wrist & r \\
\hline Pat. 20 & Male & 55 & Violin & 12 & 54 & 42 & 1 & Wrist & $r$ \\
\hline Pat. 21 & Male & 59 & Violin & 12 & 49 & 37 & 10 & Elbow & $r$ \\
\hline Pat. 22 & Male & 55 & Oboe & 13 & 54 & 41 & 1 & Elbow & 1 \\
\hline Pat. 23 & Male & 38 & Percussion & 14 & 33 & 19 & 5 & Wrist & I \\
\hline
\end{tabular}


Table 1 Patients' characteristics of all 23 patients with a task specific tremor at the instrument (Continued)

\begin{tabular}{|c|c|c|c|c|c|c|c|c|c|c|}
\hline & $\begin{array}{l}\text { Type B } \\
\text { tremor }\end{array}$ & $\begin{array}{l}\text { Spreading } \\
\text { of tremor }\end{array}$ & Previous trauma & Medication & $\begin{array}{l}\text { Botulinum } \\
\text { toxin }\end{array}$ & $\begin{array}{l}\text { Ethanol } \\
\text { responsive }\end{array}$ & $\begin{array}{l}\text { Family history for } \\
\text { movement disorders }\end{array}$ & DBS & $\begin{array}{c}\text { Tremor } \\
\text { frequency }(\mathrm{Hz})\end{array}$ & $\begin{array}{l}\text { Still plays in } \\
\text { the orchestra }\end{array}$ \\
\hline Pat. 1 & $n$ & $y$ & y (overuse) & Thx & $y$ & $n$ & $n$ & $n$ & 7.3 & $n$ \\
\hline Pat. 2 & $\mathrm{n}$ & y & y (car accident) & Prop, Thx, Gabap,Topi, Prim & y & y & y (WC) & $n$ & 6.4 & y \\
\hline Pat. 3 & $n$ & y & $n$ & Prim, Prop & $n$ & y & $y$ (tremor) & $n$ & 4.9 & y \\
\hline Pat. 4 & $n$ & y & $n$ & Prim, Prop & y & y & $n$ & $n$ & 6.8 & y \\
\hline Pat. 5 & y & $n$ & y (overuse) & Prop, Thx & $n$ & $n$ & $n$ & $n$ & 6.4 & y \\
\hline Pat. 6 & $n$ & $n$ & $n$ & Thx, Mad, Cip, Prop & $n$ & $?$ & $n$ & $n$ & 6.8 & Student \\
\hline Pat. 7 & $\mathrm{n}$ & $n$ & y (finger injury) & Thx & $\mathrm{n}$ & $\mathrm{n}$ & $\mathrm{n}$ & $n$ & 8.3 & y \\
\hline Pat. 8 & $\mathrm{n}$ & y & y (overuse) & Prop, Thx & $\mathrm{n}$ & $?$ & $\mathrm{n}$ & $\mathrm{n}$ & 7.1 & y \\
\hline Pat. 9 & y & $n$ & $n$ & Prop & $n$ & $n$ & y (tremor, PD) & $n$ & 4.6 & y \\
\hline Pat. 10 & y & y & $\mathrm{n}$ & Thx & $\mathrm{n}$ & y & $\mathrm{n}$ & $n$ & 6.8 & Teacher \\
\hline Pat. 11 & $n$ & $n$ & y (fracture radius + ulna) & Prop & $n$ & $?$ & $n$ & $n$ & 6.1 & y \\
\hline Pat. 12 & $\mathrm{n}$ & $n$ & $n$ & none & $\mathrm{n}$ & $\mathrm{n}$ & $n$ & $n$ & 5.1 & Retired \\
\hline Pat. 13 & $n$ & y & $n$ & Prop & y & y & $\mathrm{n}$ & $n$ & 6.4 & y (Big Band) \\
\hline Pat. 14 & $n$ & y & $n$ & Prop, Prim & y & $n$ & $\mathrm{n}$ & $n$ & 6.4 & y \\
\hline Pat. 15 & y & $n$ & y (surgery shoulder) & Vfx, Mtz, Loraz, Thx & $n$ & $?$ & $n$ & $n$ & 6.6 & y \\
\hline Pat. 16 & y & y & $n$ & Prop, Mad & $n$ & $n$ & $n$ & $n$ & 6.4 & y \\
\hline Pat. 17 & $n$ & $n$ & $n$ & Prop & $n$ & $n$ & $n$ & $n$ & 6.4 & Student \\
\hline Pat. 18 & y & $n$ & $\mathrm{n}^{*}$ & Thx, Cip, Mad & $n$ & $n$ & y & $n$ & 6.8 & y \\
\hline Pat. 19 & y & $n$ & y (surgery rotaor cuff) & Bromazepam & $\mathrm{n}$ & $\mathrm{n}$ & $y(E T)$ & $n$ & 7.6 & y \\
\hline Pat. 20 & y & $n$ & y (pain shoulder) & Prop & $n$ & y & $y(E T)$ & $n$ & 6.1 & y \\
\hline Pat. 21 & y & $n$ & $n$ & - & $n$ & $?$ & $y(E T)$ & $n$ & 7.8 & Teacher \\
\hline Pat. 22 & y & y & $n$ & Prop & $\mathrm{n}$ & $\mathrm{n}$ & $y(E T)$ & $n$ & 6.1 & Self employed \\
\hline Pat. 23 & $n$ & y & $\mathrm{n}$ & Cip, Prop & $n$ & $n$ & y (PD) & $n$ & - & y \\
\hline
\end{tabular}




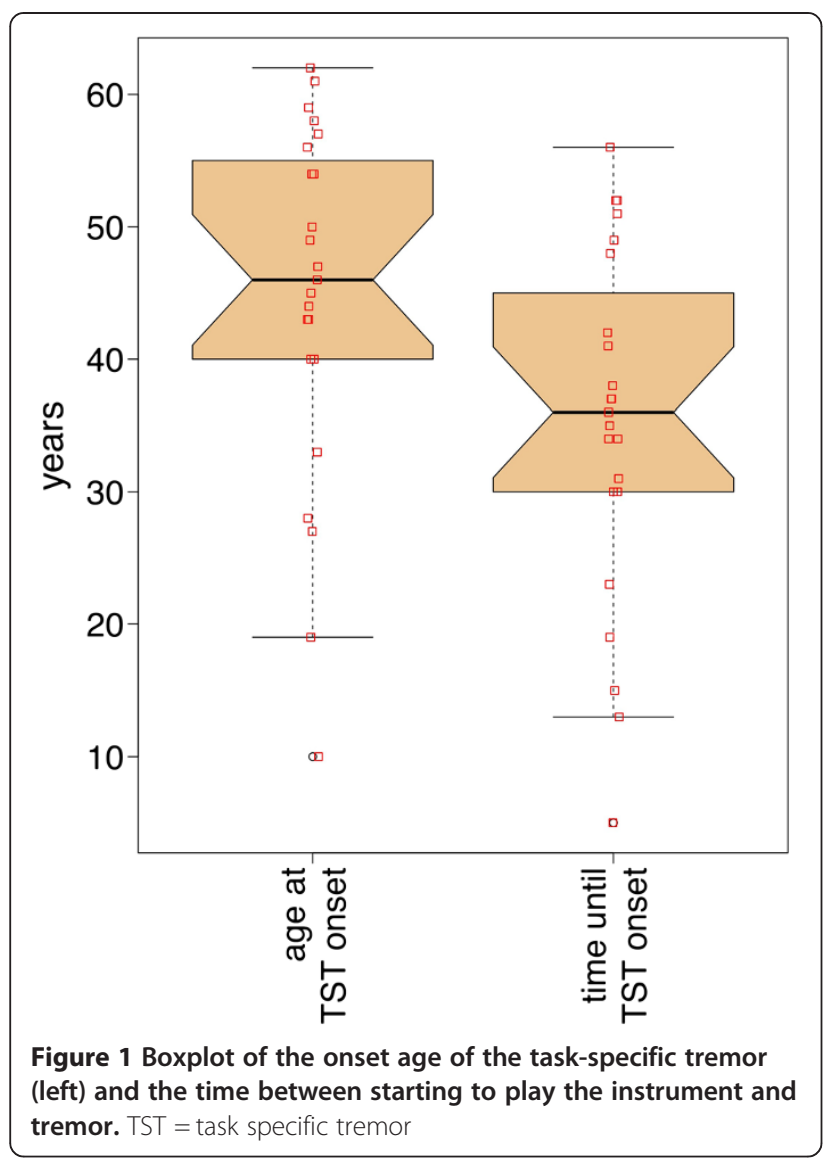

with amounts of 10-117.5 Units or 5-23.4 Units/muscle, where the amount of muscles varied between two and six. No adverse events were reported under this treatment. Four of these patients reported an improvement of tremor $(80 \%)$. Treatment and response to treatment are given in Table 2 and Figure 2.

\section{Gender distribution}

$\chi^{2}$-test assuming an equal gender distribution ( $\left.\mathrm{f}: \mathrm{m}=1: 1\right)$ demonstrated that $X^{2}=9.8, \mathrm{df}=1$, and $\mathrm{p}=0.002 . X^{2}$-test assuming a gender distribution as in musicians dystonia ( $\mathrm{f}: \mathrm{m}=1: 4$ ) showed $\chi^{2}=0.1, \mathrm{df}=1, \mathrm{p}=0.8$.

A summary of epidemiology, phenomenology and treatment in this study, in PBT and in PWT is given in Table 3.

\section{Discussion}

Tremor frequency corresponds to what has been found in PWT $[5,6,8,12]$. The main differences to PWT are firstly that we found an involvement of proximal muscles, which to our knowledge has not been reported in PWT. The necessity to hold the entire arm against gravity while playing the instruments in contrast to writing may be an explanation for this phenomenon. Secondly type B tremor occurs more often in TSTM than in PWT $[5-8,12,14,19]$. This is interesting because it supports the notion that the tonic nature of playing the affected instruments as mentioned above seems to play a role in TSTM. No difference to PWT [5-8,12,14,19] was found with regard to alcohol responsiveness, although a wide range between 0\% [14] and 75\% [6] exists in PWT (Table 3). Spreading of tremor to other tasks as we found in TSTM is a phenomenon described in TST and a strict taskspecificity was questioned recently $[5,19,23]$. An evolution of the disorder over time [19] was discussed that may apply to TSTM, as well.

The mean onset age of TSTM is 43.5 years and does not differ to PBT $[1,2]$ and is only marginally lower than in PWT $[5-8,12,14,19]$ (Table 3). The high standard deviation in PBT [2] and in PWT [5-8,12,14,19] reflects the great range of the age at tremor onset (Table 3). Tremor appeared on average 35 years after starting to exert the triggering task, an information to our knowledge not reported in PWT. However there is a wide range of 5 years to more than 50 years. Mean tremor-affected duration of our patients was $7.6 \pm 5.2$ years. In this context it is noteworthy that only one of the musicians playing in an ensemble had to stop playing because of tremor and all musicians who are primarily teaching continue to exert their profession. One musician was retired (Table 3). This is an important finding, since for most musicians tremor poses a serious threat to their professional career. Which treatments are available that may allow patients to continue performing (Table 3)? Botulinum-toxin-injection with a response rate of $80 \%$ was the most effective treatment. High response rates have been reported in PWT $[5,14,15]$, where it was fond to be the second-best rated treatment after deep brain stimulation [19]. The most effective oral medication was Primidone with a response rate of $75 \%$. Propranolol was the most often prescribed

Table 2 Medications prescribed

\begin{tabular}{lcccccccccc}
\hline & Prop & Thx & Prim & Madop & Gabap & Cip & Ven & Topi & Loraz & Btx* \\
\hline Number of patients & 15 & 10 & 4 & 3 & 1 & 3 & 1 & 1 & 1 & 5 \\
Improvement & 9 & 2 & 3 & 0 & 0 & 0 & 0 & 0 & 1 & 4 \\
No improvement & 6 & 8 & 1 & 3 & 1 & 3 & 1 & 1 & 0 & 1 \\
Dosage & $5-80 \mathrm{mg}$ & $6 \mathrm{mg}$ & $60 \mathrm{mg}$ & $62.5 \mathrm{mg}$ & $2.4 \mathrm{~g}$ & $10 \mathrm{mg}$ & $150 \mathrm{mg}$ & $200 \mathrm{mg}$ & $1 \mathrm{mg}$ & $5-23.4 / \mathrm{muscle}$ \\
\hline
\end{tabular}

*Units of Dysport ${ }^{\oplus}$ were converted intor units of Botox ${ }^{\oplus}$ with the factor 3:1. Thx = Trihexyphendyl; Gabap = Gabapentine; Madop = Madopar; Prop = Propranolol; Prim = Primidone; Cip = Citalopram; Ven = Venlafaxin; Topi $=$ Topiramate; Loraz $=$ Lorazepam; Btx $=$ Botulinumtoxin; resp $=$ responder; non-resp $=$ non-responder. 


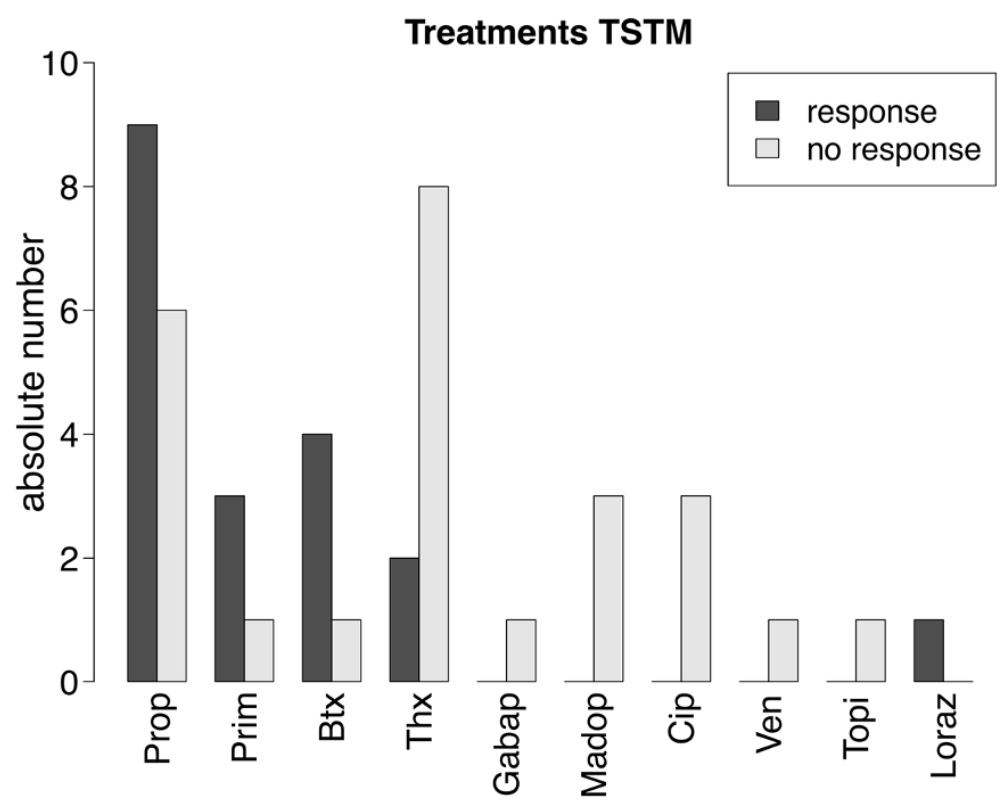

Figure 2 Response to treatments given in our study in absolute numbers. TSTM = Task specific tremor in instrumentalists; Prop = Propranolol; Prim = Primidone; Btx = Botulinumtoxin; Thx = Trihexyphenidyl; Gabap = Gabapentine; Madop = Madopar; Cip = Cipralex; Ven = Venlafaxine; Topi $=$ Topiramate; Loraz $=$ Lorazepam .

treatment and beneficial for $60 \%$ of our patients, although, as in PWT [6-8] improvement was not related to the dosage: one patient reported an improvement under $5 \mathrm{mg}$ whereas $80 \mathrm{mg}$ did not have any effect in another patient. As in PWT $[5,7,8,14]$, Trihexyphenidyl was beneficial for only $20 \%$ of the patients, although one patient had an almost complete remission. The effect of Lorazepam, taken by one patient was due to reduction of stress caused by the tremor. None of the other medications had any effect. Treatment in PWT and PBT are given in Table 2.

None of our patients has undergone DBS so far, although two had considered it. The main concern is the lack of experience with DBS in musicians as well as high expectations of a complete remission. Therefore a recent case report of an oboist with TST is of interest, where a marked improvement through bilateral stimulation of the ventralis intermedius nucleus was reported [24]. In PWT several reports of successful treatment with DBS of the thalamus exist $[9,11,17]$.

The response to Primidone and Propranolol is suggestive of essential tremor and it remains under debate whether task-specific tremors are a form of essential tremor, of focal dystonia or an entity of its own [7,18,23,25].

The high prevalence of string and woodwind instrumentalists has been reported before in a study by Lederman [21]. It has to be noted, however, that in the study by Lederman tremors other than TST were included. It is of interest that in the present study that includes only patients with TSTM, tremor is much more common in instrumentalists requiring steady (tonic) postural muscular activity (holding the bow, the oboe etc.) as in instrumentalists mainly relying on phasic and ballistic movements such as pianists and percussionists. This of course may be related to the professional consequences, in that postural tremor reduces perceived sound quality to a much higher degree as compared to tremor in phasic movements.

A recent study of five string instrumentalists with PBT consisted of three female and two male participants suggesting an female gender predominance [2], however, due to the small sample size general conclusions were difficult. Our test for gender distribution suggests a male gender predominance in TSTM that does not differ to musician's dystonia [22] or PWT.

Of our patients, 39\% reported a trauma of the affected limb prior to tremor onset, which is known from PWT, albeit at a lower prevalence (19\% [5] and 30\% [6]), however, we are aware that this question is subject to recall bias. Whether traumata are related to the development of TST, however, cannot be concluded from our data alone. One patient had a dystonia that had markedly improved before developing tremor and during examination at the instrument no dystonic posturing was visible and only tremor was evident. This is interesting, because dystonia preceding PWT was described by Bain et al. [5] and likewise tremor preceding dystonia has been described before [26]. A positive family history as risk factor was found in PBT [2] as well as in PWT, although in PWT, two studies reported no family history in ten [6] or five [14] patients respectively (Table 3 ). 
Table 3 Summary of epidemiology, phenomenology and treatment in this study, in primary bowing tremor (PBT) and primary writing tremor (PWT)

\begin{tabular}{|c|c|c|c|c|c|c|c|c|c|c|}
\hline & $\begin{array}{c}\text { Mean age } \\
\text { at onset (yrs) }\end{array}$ & $\begin{array}{l}\text { SD of onset } \\
\text { age (yrs) }\end{array}$ & & $\begin{array}{l}\text { Sample } \\
\text { size }\end{array}$ & Type B & $\begin{array}{l}\text { Alcohol } \\
\text { responsive }\end{array}$ & & Antichol & $\begin{array}{l}\text { Dosage } \\
\text { per day }\end{array}$ & Prop \\
\hline \multicolumn{11}{|l|}{ TST in musicians } \\
\hline This paper & 51.5 & \multicolumn{2}{|l|}{11.4} & $n=23$ & $10(43 \%)$ & \multicolumn{2}{|l|}{ 6/18 (33\%) } & $2 / 10(20 \%)$ & $6 \mathrm{mg}$ & $9 / 15(60 \%)$ \\
\hline \multicolumn{11}{|l|}{ PBT } \\
\hline Lederman [2] & 41 & \multicolumn{2}{|l|}{23.2} & $n=5$ & $2(40 \%)$ & \multicolumn{2}{|l|}{$1 / 1(100 \%)$} & $0 / 1$ & $6 \mathrm{mg}$ & $1 / 1(100 \%)$ \\
\hline \multicolumn{11}{|l|}{ PWT } \\
\hline Rosenbaum \& Jankovic [7] & 50.5 & \multicolumn{2}{|l|}{14.8} & $n=10$ & $3(30 \%)$ & \multicolumn{2}{|l|}{$2 / 4(50 \%)$} & $4 / 5(80 \%)$ & - & $4 / 4(100 \%)$ \\
\hline Bain et al. [5] & 50.1 & \multicolumn{2}{|l|}{ range (16-76) } & $n=21$ & $10(48 \%)$ & $7 / 17(41 \%)$ & \multicolumn{2}{|r|}{ 4/12 (33\%) } & - & $4 / 12(33 \%)$ \\
\hline Kachi et al. [6] & 40.8 & \multicolumn{2}{|l|}{18.1} & $n=10^{*}$ & $3(30 \%)$ & \multicolumn{2}{|l|}{$3 / 4(75 \%)$} & - & - & 10/11 (91\%)\# \\
\hline Elble et al. [8] & 37 & \multicolumn{2}{|l|}{13.9} & $n=5$ & $2(40 \%)$ & \multicolumn{2}{|l|}{$1 / 4(25 \%)$} & 1/3 (33\%)\#\# & $12-15 \mathrm{mg}++$ & $0 / 3(0 \%)$ \\
\hline Modugno et al. [12] & 51.7 & \multicolumn{2}{|l|}{16.2} & $n=7$ & $1(14 \%)$ & \multicolumn{2}{|l|}{ - } & - & - & - \\
\hline Ondo \& Satija [19] & 47.2 & \multicolumn{2}{|l|}{18} & $n=56$ & $11(20 \%)$ & - & & - & - & $31^{* *}$ \\
\hline Papapetropoulos \& Singer [14] & 48.4 & 15.5 & & $n=5$ & $2(40 \%)$ & $0 / 5$ & & $1 / 2(50 \%)$ & $6 \mathrm{mg}$ & - \\
\hline & $\begin{array}{l}\text { Dosage } \\
\text { per day }\end{array}$ & Prim & $\begin{array}{l}\text { Dosage } \\
\text { per day }\end{array}$ & & BTX & $\begin{array}{l}\text { Dosage } \\
\text { per day }\end{array}$ & $\begin{array}{l}\text { Family } \\
\text { history }\end{array}$ & Trauma & $\begin{array}{c}\text { Tremor } \\
\text { frequency }(\mathrm{Hz})\end{array}$ & Ratio f:m \\
\hline TST in musicians & & & & & & & & & & \\
\hline This paper & $5-80 \mathrm{mg}$ & $3 / 4(75 \%)$ & $60 \mathrm{mg}$ & & $4 / 5(80 \%)$ & $5-23.4 \mathrm{U} / \mathrm{m}$ & $9(39 \%)$ & $9(39 \%)$ & $6.5(+-0.9)$ & 4:19 \\
\hline PBT & & & & & & & & & & \\
\hline Lederman [2] & $20 \mathrm{mg}$ & - & - & & - & - & $2(40 \%)$ & - & - & $3: 02$ \\
\hline PWT & & & & & & & & & & \\
\hline Rosenbaum \& Jankovic [7] & - & - & - & & - & - & $3(30 \%)$ & - & - & 3:07 \\
\hline Bain et al. [5] & - & $3 / 4(75 \%)$ & $62.5-125 \mathrm{mg}$ & & $2 / 2(100 \%)$ & $33 \mathrm{U} / \mathrm{m}$ & 7 (33\%) & $4(19 \%)$ & $5.5(4.1-7.3)$ & $1: 20$ \\
\hline Kachi et al. [6] & $120-240 \mathrm{mg}+$ & - & - & & - & - & 0 & $3(30 \%)$ & 5 -Jun & 2:08 \\
\hline Elble et al. [8] & $240 \mathrm{mg}$ & $0 / 2(0 \%)$ & $750 \mathrm{mg}$ & & - & - & $1(20 \%)$ & - & 5-Jul & 1:04 \\
\hline Modugno et al. [12] & - & - & - & & - & - & $3(43 \%)$ & - & $5-J u l$ & 1:06 \\
\hline Ondo \& Satija [19] & - & $18^{* *}$ & - & & $17^{* *}$ & - & $27(48 \%)$ & - & - & 41:15:00 \\
\hline Papapetropoulos \& Singer [14] & - & - & - & & $4 / 4(100 \%)$ & $10-12.5 \mathrm{U} / \mathrm{m}$ & 0 & - & - & 2:03 \\
\hline
\end{tabular}

*One patient had golfing tremor; \# in five patients propranolol was administered intravenously and not orally, of whom 4 resonded; +only orally administered propranolol; \#\#2xtrihexyphenidyl, 1xbenztropine (no effect); ++dosage only for trihexyphenidyl; **only the number of treated patients was reported with a mean rating of success; \#\# not includeing the range given by Bain et al. Abbreviations: TST Task-specific tremor, PBT Primary bowing tremor, PWT Primary writing tremor, yrs years, SD standard deviation, Type B type B task-specific tremor, Antichol anticholinergic medication, Prop propranolol, Prim primidone, $f$ female, $m$ male, appr approximately.

medicament/alcohol in the respective study. 


\section{Conclusion}

To our knowledge, this is the largest sample of TSTM described in detail so far. It is a heterogeneous disorder that shares many commonalities with PWT. It occurs mainly between the age of 30 and 55, appears between 21 and 48 years after starting to play the instrument and has a male gender predominance. It may spread to other tasks. Because previous trauma may precede TSTM, it is important to raise awareness for preventive measures against playing related injuries as e.g. overuse. There appears to be a genetic predisposition for TST. A variety of treatment options exist, of which most beneficial are Botulinumtoxin, Propranolol, and Primidone. Since no single beneficial medication exists, treatment of patients remains highly individual. Given the positive results of DBS in PWT and the positive case report of an oboist with TSTM, it should be discussed, whether this should be offered not only to patients that do not respond to any other medication but early in the course of the disease. However, further studies are necessary to address this question.

\section{Competing interests}

The authors declare that they have no competing interests.

\begin{abstract}
Authors' contribution
$\mathrm{AL}$ : Conception and design of the study, acquisition, analysis and interpretation of data. Drafting of the manuscript. Final approval. Agrees to be accountable for all aspects of the work in ensuring that questions related to the accuracy or integrity of any part of the work are appropriately investigated and resolved. SF: Analysis and interpretation of data. Revision of manuscript for important intellectual content. Final approval. Agrees to be accountable for all aspects of the work in ensuring that questions related to the accuracy or integrity of any part of the work are appropriately investigated and resolved. EA: Conception and design of the study, interpretation of data. Revision of manuscript for important intellectual content. Final approval. Agrees to be accountable for all aspects of the work in ensuring that questions related to the accuracy or integrity of any part of the work are appropriately investigated and resolved. All authors read and approved the final manuscript.
\end{abstract}

\section{Acknowledgements}

Funding for AL and EA: Hannover University of Music, Drama and Media.

Received: 26 March 2014 Accepted: 3 June 2014

Published: 4 December 2014

\section{References}

1. Lee A, Chadde M, Altenmüller E, Schoonderwaldt E: Characteristics of task-specific tremor in string instrument players. Tremor Hyperkinetic Mov N Y N 2013. in press.

2. Lederman RJ: Primary bowing tremor: a task-specific movement disorder of string instrumentalists. Med Probl Perform Art 2012, 27:219-223.

3. Lee A, Tominaga K, Furuya S, Miyazaki F, Altenmüller E: Coherence of coactivation and acceleration in task-specific primary bowing tremor. J Neural Transm Vienna Austria 1996 2014. epub ahead of print. doi:10.1007/s00702-014-1177-3.

4. Rothwell JC, Traub MM, Marsden CD: Primary writing tremor. J Neurol Neurosurg Psychiatry 1979, 42:1106-1114.

5. Bain PG, Findley LJ, Britton TC, Rothwell JC, Gresty MA, Thompson PD, Marsden CD: Primary writing tremor. Brain J Neurol 1995, 118(Pt 6):1461-1472.

6. Kachi T, Rothwell JC, Cowan JM, Marsden CD: Writing tremor: its relationship to benign essential tremor. J Neurol Neurosurg Psychiatry 1985, 48:545-550.
7. Rosenbaum F, Jankovic J: Focal task-specific tremor and dystonia: categorization of occupational movement disorders. Neurology 1988, 38:522-527.

8. Elble RJ, Moody C, Higgins C: Primary writing tremor. A form of focal dystonia? Mov Disord Off J Mov Disord Soc 1990, 5:118-126.

9. Minquez-Castellanos A, Carnero-Pardo C, Gómez-Camello A, Ortega-Moreno A, García-Gómez T, Arjona V, Martin-Linares JM: Primary writing tremor treated by chronic thalamic stimulation. Mov Disord Off J Mov Disord Soc 1999, 14:1030-1033.

10. Berg D, Preibisch C, Hofmann E, Naumann M: Cerebral activation pattern in primary writing tremor. J Neurol Neurosurg Psychiatry 2000, 69:780-786.

11. Racette BA, Dowling J, Randle J, Mink JW: Thalamic stimulation for primary writing tremor. J Neurol 2001, 248:380-382.

12. Modugno N, Nakamura Y, Bestmann S, Curra A, Berardelli A, Rothwell J: Neurophysiological investigations in patients with primary writing tremor. Mov Disord Off J Mov Disord Soc 2002, 17:1336-1340.

13. Byrnes ML, Mastaglia FL, Walters SE, Archer S-AR, Thickbroom GW: Primary writing tremor: motor cortex reorganisation and disinhibition. J Clin Neurosci Off J Neurosurg Soc Australas 2005, 12:102-104.

14. Papapetropoulos $S$, Singer C: Treatment of primary writing tremor with botulinum toxin type a injections: report of a case series. Clin Neuropharmacol 2006, 29:364-367.

15. Singer C, Papapetropoulos S: Adult-onset primary focal foot dystonia. Parkinsonism Relat Disord 2006, 12:57-60.

16. Ljubisavljevic M, Kacar A, Milanovic S, Svetel M, Kostic VS: Changes in cortical inhibition during task-specific contractions in primary writing tremor patients. Mov Disord 2006, 21:855-859.

17. Blomstedt $\mathrm{P}$, Fytagoridis A, Tisch S: Deep brain stimulation of the posterior subthalamic area in the treatment of tremor. Acta Neurochir (Wien) 2009, 151:31-36.

18. Hai C, Yu-ping W, Hua W, Ying S: Advances in primary writing tremor. Parkinsonism Relat Disord 2010, 16:561-565.

19. Ondo WG, Satija P: Task-specific writing tremor: clinical phenotypes, progression, treatment outcomes, and proposed nomenclature. Int J Neurosci 2012, 122:88-91.

20. Meunier S, Bleton JP, Mazevet D, Sangla S, Grabli D, Roze E, Vidailhet M: TENS is harmful in primary writing tremor. Clin Neurophysiol 2011, 122:171-175.

21. Lederman RJ: Tremor in instrumentalists: influence of tremor type on performance. Med Probl Perform Art 2007, 22:70-73.

22. Altenmüller $\mathrm{E}$, Jabusch $\mathrm{H}$-C: Focal dystonia in musicians: phenomenology, pathophysiology, triggering factors, and treatment. Med Probl Perform Art 2010, 25:3-9.

23. Bain PG: Task-specific tremor. Handb Clin Neurol Ed PJ Vinken GW Bruyn 2011, 100:711-718.

24. Whitney N, Kareus S, Cetas JS, Chung K, Brodsky M: Bilateral deep brain stimulation targeting ventralis intermedius nucleus to treat a professional musician's task-specific tremor. Mov Disord Off J Mov Disord Soc 2013, 28:1896-1897.

25. Deuschl G, Bain P, Brin M: Consensus statement of the movement disorder society on tremor. Ad Hoc scientific committee. Mov Disord Off J Mov Disord Soc 1998, 13 Suppl 3:2-23.

26. Schiebler S, Schmidt A, Zittel S, Bäumer T, Gerloff C, Klein C, Münchau A: Arm tremor in cervical dystonia-is it a manifestation of dystonia or essential tremor? Mov Disord Off J Mov Disord Soc 2011, 26:1789-1792.

doi:10.1186/2054-7072-1-5

Cite this article as: Lee et al.: Epidemiology and treatment of 23 musicians with task specific tremor. Journal of Clinical Movement Disorders 2014 1:5. 